\title{
Factors of Self-Esteem Contributing to Academic Performance in Adolescents
}

\author{
Megha Pushkarna ${ }^{1}$
}

\begin{abstract}
The focus of the study was to find out whether factors of self-esteem and certain socio-demographic factors contribute towards academic performance in adolescents.

Sample: The sample consisted of students taken from classes (VII-XII) from one school and their age ranged between 12 and 17 years; thus the final sample taken was of 727 students.

M ethodology: The tools used in this research were Coopersmith Self-Esteem Inventory (SEI), Sociodemographic Questionnaire and previous year final-term scores.

Analysis of Data: Data was analyzed using Pearson's correlation, t-test, F-test, ANOVA and Post hoc Tukey.

Conclusion: Self-esteem as a whole and its four sub factors correlated significantly with academic performance. That is, higher the self-esteem, higher was the academic performance. Of the four sub factors, school self-esteem factor appeared to have the highest correlation and home self-esteem appeared to have lowest correlation with academic performance.

Self-esteem differed significantly in terms of socio-demographic variables (i.e., age, gender and family type). Academic performance differed significantly in terms of socio-demographic variables (i.e., age, gender and birth order).
\end{abstract}

Keyw ords: Self-esteem, Academic performance, Adolescents

"Self-esteem is a personal judgment of worthiness that is expressed in the attitudes the individual holds toward himself" (Coopersmith). ${ }^{5}$

\footnotetext{
*Senior Consultant, Department of Communication Research, Indian Institute of Mass Communication, New JNU Campus, Aruna Asaf Ali Marg, New Delhi-110067.
}

E-mail Id: meghapushkarna@gmail.com

Orcid Id: http:// orcid.org/0000-0003-0179-030X

How to cite this article: Pushkarna M. Factors of Self-Esteem Contributing to Academic Performance in Adolescents. Ind J Youth Adol Health 2017; 4(2): 17-25.

Digital Object Identifier (DOI): https:// doi.org/10.24321/2349.2880.201712

ISSN: 2349-2880 


\section{Introduction}

\section{Concept of Self-esteem}

According to Branden, "Self-esteem when fully realized, is the experience that is appropriate to the requirements of life" . ${ }^{3}$ Being more specific, self-esteem is:

- Confidence in our ability to think, cope with the basic challenges of life; and

- Confidence in our right to be successful and happy, of being worthy, deserving, entitled to assert our needs and wants, achieve our values, and enjoy the fruits of our efforts.

Self-esteem is regarded as an important aspect of one's social and cognitive development, with the early adolescent years being somewhat volatile ${ }^{2}$ and yielding substantial shifts from one year to the next. ${ }^{6} \mathrm{M}$ any studies have been conducted into the effects of selfesteem on different outcomes during the teenage years, including academic performance and overall adjustment. ${ }^{7,9,16}$

Researchers like Allan $\&$ Nairne ${ }^{1}$ stated that emphasis on self-esteem has been given importance due to the effects of poor self-esteem on students and consequently the school climate. Self-esteem is not only an important educational outcome but it also facilitates other desirable outcomes (M arsh, 1993).

\section{Importance of Self-esteem and Academic Performance in Adolescents}

While self-esteem refers to the students' view of themselves as worthy and of value, academic performance, particularly if high and praise worthy, adds to the self-esteem and is also considered to be a reliable indicator of future performance in academics.

The relationship involving self-esteem and academic results does not only signify that high self-esteem contributes to high academic results; it also means that self-esteem may get enhanced due to high academic performance as well as due to other life events affecting performance. The most important thing here is to appreciate the interaction and the reciprocal dynamics between self-esteem and achievement as they seem to be mutually reinforcing.

According to the popular self-esteem model of Ross and Broh, ${ }^{13}$ adolescents who feel good about themselves appear to do better in school than those who have low self-worth (a term commonly interrelated with selfesteem). Also self-esteem has been considered to playa major role in learning outcomes ${ }^{8}$ and the school on its part is considered to influence the process of enhancing self-esteem. ${ }^{12}$

The above findings confirm a strong, positive relationship and a continuous interaction between these two factors, thus studying them together can serve students, teachers, counselors and anyone working in the school environment in a beneficial manner.

If poor performance in academics can lead to a negative view of oneself, then knowing this serves as an important motivator in measuring the relationship between self-esteem and academic achievement. ${ }^{11}$

\section{Aim of the Present Research}

The researcher felt and has observed that students in adolescents years tend to be highly introspective and self-conscious. Their thoughts often center on their fears, desires, beliefs, attitudes and expectations. Also their feelings about self vary considerably. If students get better grades than others and feel more competent in a particular subject in relation to other students, positive self-evaluations may be the consequence. Thus, good grades and healthy peer comparison leads to a relatively high academic self-concept in that subject and vice-versa.

It has been noticed that middle school students are generally considered to react negatively when they experience a setback in academics, which may affect their self-esteem to quite an extent. This is so because this stage of development brings forth considerable biological, physiological, psychological changes to face along with challenging environment to get promoted to a higher class.

Most often, students' self-esteem may be adversely affected due to the high expectations of teachers and parents, changing value systems, financial problems, peer pressure and in certain cases break up of family, poor school and family environment.

Healthy self-esteem at the middle and senior school level can help in building healthy perceptions of competence, coping skills, social support and a variety of other qualities that are likely to equip students to succeed in school.

Previous researches have focused on effects of low selfesteem using Rosenberg's self-esteem scale extensively, with peer attachment and academic performance to assess adolescents. The present research uses Coopersmith Self-Esteem Inventory (SEI) as a tool to analyze and understand factors of self-esteem 
contributing to academic performance in the Indian context.

The researcher chose Coopersmith Self-Esteem Inventory (SEI) over Rosenberg as the latter evaluates only global and specific self-esteem as compared to former which looks into four core areas (General, Social, Home and School) of students' self-esteem. The researcher felt SEl could highlight core issues that have significant value to adolescents with respect to their self-opinion and significantly impact their future learning outcomes (i.e., performance in school).

\section{Educational Implications of the Research}

Maslow ${ }^{10}$ suggests students must be shown that they are valued and respected in the classroom and the teacher should create a supportive environment. Students with a low self-esteem will not progress academically at an optimum rate until their self-esteem is strengthened.

For many children, school represents a "second chance" - an opportunity to acquire a better sense of self and a better vision of life than was offered at home.

A teacher who projects confidence in a child's competence and goodness can be a powerful antidote to a family in which such confidence is lacking and in which perhaps the opposite perspective is conveyed. M ost teachers want to make a positive contribution to the minds entrusted in their care and today most are aware that one of the ways they can contribute is by nurturing the students' self-esteem. They know that students who believe in themselves and whose teachers project a positive view of their potential, do better in school than the ones without these advantages.

Present research is action oriented in that it may throw light on the need for intervention at school level by teachers and counsellors. It takes into account acknowledging, exploring and assisting students in getting a deeper insight into their self- evaluations with regard to academic successes and also dealing with setbacks. A group-based intervention with standardized lessons can easily be incorporated into established curricula or adapted to fit the needs of a particular school and can be supervised by counselors.

Fostering of self-esteem must be integrated in school curricula to support young people in persevering with their studies, gaining education they need and to prepare them psychologically for a world in which the mind is everyone's chief capital asset.

\section{Methodology}

Keeping the above in view following objectives were formulated.

\section{Objectives}

[1]. To find out the relationship between self-esteem and academic performance of the students.

[2]. To find out if different factors of self-esteem relate significantly to academic performance.

\section{[3]. To ascertain if self-esteem differs in terms of}
$\left(a_{1}\right)$ Age and $\left(a_{2}\right)$ gender
(b) Type of family to which the students belong
(c) Their birth order in the family
(d) Their parent/s working outside home

[4]. If there is a difference in academic performance in terms of
$\left(a_{1}\right)$ Age and $\left(a_{2}\right)$ gender
(b) Type of family to which the students belong
(c) Their birth order in the family
(d) Their parent/s working outside home

Direct observation, interviews and projective measures are often used formally and informally to assess selfesteem. While the result of one's appraisal of selfesteem may remain consistent over a period of several years, momentary or short-lived changes can and do occur. Thus, Coopersmith's Self-esteem Inventory (SEI) was used with last year academic scores, questionnaire, and group sessions to understand factors of students' self-esteem contributing towards their academic performance.

Based on this statement, the following hypotheses have been formulated.

Hypothesis 1: There will be a significant relationship between self-esteem and academic performance of adolescent students.

Hypothesis 2: Different factors of self-esteem (General, Social, Home and School) will relate significantly to academic performance.

Hypothesis 3: Self-esteem scores of students will vary in relation to their
$\left(a_{1}\right)$ Age and $\left(a_{2}\right)$ gender
(b) Family type/structure
(c) Birth order
(d) Parental occupation 
Hypothesis 4: Academic performance of students will differ in terms of their

$\left(a_{1}\right)$ Age and $\left(a_{2}\right)$ gender

(b) Type of family to which they belong

(c) Birth order

(d) Parental occupation

\section{Operational Definitions}

(i) Academic performance: Academic performance refers to the previous year's final examination aggregate marks obtained by the student (on the basis of which the student is promoted to the next class).

(ii) Age: Age has been taken as obtained from their school record.

(iii) Birth order: Birth order refers to the first born, middle and last born. Middle includes all those who are not in the eldest or youngest category.

(iv) Family type: Nuclear families refer to where parents and their children live together; joint family refers to the children, their parents and grandparents or uncles and aunts and their children living together under one roof.

(v) Parents working outside home: This refers to either one or both parents working outside of the house.

(vi) General self-esteem: According to Coopersmith, it is the opinion one has of oneself, their selfconcept and the conclusion about oneself, based on the feedback they get from significant others.

(vii) Social self-esteem: It refers to the extent to which a student feels comfortable and secure in the emotional and social relationship. It draws upon the sense of happiness with one's own selfidentity, quality of peer relationships, their sense of being valued, their social centrality and their enjoyment at school.

(viii) Home self-esteem: This is self-acquired by the student based on their experiences as to how their parents and other significant people in their lives feel about/treat them. This also includes the feeling that they have a place in the society and that they are part of a family where they are important.

(ix) School self-esteem: This refers to the self-esteem acquired as a result of one's performance, feelings of success and popularity in the school. School for an adolescent becomes a crucial place to succeed as that is where the maximum interaction with their peers takes place.

Also school is important as parents relate their child's development with the way they perform academically in the school. Thus students doing well in school appear to have a higher self-opinion about themselves.

\section{Research Design}

Present research used a correlational design which aims to delineate how far self-esteem dimensions relate to academic performance of students. Also a comparative design has been used to find out if self-esteem or academic performance differs in terms of sociodemographic factors. In order to test the hypotheses, the following variables have been used.

(i) Dépendent variable: Academic performance.

(ii) Independent variable: Self-esteem at four levels (General, Social, Home, and School) and sociodemographic variables (age, gender, type of family, birth order and parental working out of home).

(iii) Excluding variable: Students having high lie score on SEl, learning disability or emotional distresses were excluded from this study.

\section{Tools for Data Collection}

The tools used in this research included:

(i) Coopersmith Self-Esteem Inventory (SEI) with testrest reliability of $0.64^{14}$ and concurrent validity of $0.33(\mathrm{P}<0.01) ;{ }^{15}$

(ii) Socio-demographic inventory; and

(iii) Last year's academic performance scores.

A pilot study was undertaken to test if SEl is relevant to the student group, proposed to be taken for this research. A total sample of 266 students was taken from classes VII-VIII and amongst these, two sections of class VII $(N=65)$ students were retested in a gap of one month. The test-retest reliability of SEI was (0.64) and Cronbach's coefficient alpha test for SEI was (0.78).

\section{Procedure}

The present research was conducted in a private, English-speaking school during leisure classes when students were available and for which prior permission was taken from the Principal of the school. Rapport was established between the researcher and the students and the latter were explained the purpose of research. They were also informed about the Inventory that will be given to them which they will be required to fill up.

The sample taken consisted of students from classes (VII-XII) from one school and their age ranged between 12 and 17 years covering adolescent years. As mentioned earlier, academic performance were the aggregate marks obtained by students in the final 
examination of the previous year. The scores obtained on all the scales and questionnaire were analyzed with the help of SPSS package in the computer. Thus the final sample taken was of 727 students.

\section{Results}

\section{Self-esteem and Academic Performance}

a) There was a significant and positive correlation between total self-esteem and academic performance $(r=0.15, p \varangle 0.01)$. When the academic performance was considered in three categories in terms of the aggregate marks obtained by the students, it was seen that there was a significant difference amongst the levels of academic performance and their total self-esteem scores. $(F=7.8, d f=726, p \varangle 0.01$ level).

Post hoc Tukey test (HSD) shows that the total selfesteem differed significantly between students with below and high academic performance. Hence, it may be inferred that students who scored higher in academics also showed higher self-esteem as

Table 1.Factors of Self-esteem and Academic Performance

\begin{tabular}{|c|c|c|c|c|c|}
\hline Academic Performance & Factors of Self-esteem & General SE & Social SE & Home SE & School SE \\
\hline Pearson's Correlation & 1 & $.078^{*}$ & $.085^{*}$ & $.083^{*}$ & $.255^{* *}$ \\
\hline Sig (2-tailed) & 727 & .035 & .023 & .026 & .000 \\
\hline N & & 727 & 727 & 727 & 727 \\
\hline
\end{tabular}

*Correlation is significant at the 0.05 level (2-tailed). ${ }^{* *}$ Correlation is significant at the 0.01 level (2-tailed).

As can be noted from Table 1, though the correlations appear to be rather low, the relationship is positive and significant between academic performance and selfesteem factors.

Present research shows how academic performance often divides students into groups, where high performers are considered achievers in the class and students scoring low are not seen as a part of their group.

Students doing well in studies are noticed to be favorites amongst their teachers and also given opportunities in co-curricular activities. Often it has been reported to teachers as well as counselors by the students themselves that poor performers are tagged as "failures" in school.

Due to their poor grades, which affect them considerably, it leaves them in a state of being constantly humiliated at the hands of the "toppers". At times, teachers unknowingly add to the humiliation of the student, which in turn affects the Social self-esteem compared to the students with average and belowaverage academic performance.

Present research has shown that higher self-esteem had a positive and significant influence on the academic performance of adolescents. Favorable/ Positive self-opinion of students helps to take on competition in school amongst peers as well as the teachers' and parents' appraisals. Lower selfesteem reduces the urge to succeed academically and appears to increase feelings of worthlessness, social withdrawal and in some cases delinquency.

Thus, Hypothesis 1 is validated which states that there will be a significant relationship between selfesteem and academic performance.

b) When each of the factors of self-esteem was correlated with academic performance, all the four factors of self-esteem, viz., General, Social, Home and School self-esteem had significant positive correlation with academic performance as shown in Table 1. of the students. Students look for cues of approval to be part of the "group" in their class or outside the class to feel good about themselves. When they are tagged or are let down by peers and teachers, their Social selfesteem is significantly affected.

Present research explains that students scoring high in academics had statistically higher School self-esteem as compared to those who were below average or average in academic performance. School for an adolescent is a crucial place where they have high levels of interaction with their peers and teachers (who are more often role models for them) and experience success with the marks they obtain which contributes to their selfesteem.

Furthermore, parents and significant others also consider high levels of academic performance as success of their wards in school and invariably compare their youngsters' performance with those of other children. This could be one of the reasons for children with high academic performance showing greater School selfesteem. 
Since correlation was positive, an attempt was made to find out the mean differences in self-esteem scores in terms of the students' academic performance. For the analysis, academic performance was categorized into below-average academic performance ( $0-50 \%)$, average academic performance (51-75\%) and high academic performance (76-100\%) respectively as shown in Table 2.

Table 2.Factors of Self-esteem and Three Levels of Academic Performance

\begin{tabular}{|c|c|c|c|c|}
\hline Factors of Self-esteem & Levels of Academic Performance & Mean Scores & F-Value & Sig. \\
\hline General Self-esteem & Below average & 15 & $3.6^{*}$ & 0.02 \\
& Average & 16.6 & & \\
& Above average & 16.7 & & \\
\hline Social Self-esteem & Below average & 5.3 & $3.7^{*}$ & 0.02 \\
& Average & 5.0 & & \\
\hline Above average & 5.4 & & 0.11 \\
& Below average & 5.1 & 2.1 & (NS) \\
& Average & 5.6 & & \\
\hline School Self-esteem & Above average & 4.0 & $19.8^{* *}$ & 0.00 \\
& Below average & 4.7 & & \\
\hline
\end{tabular}

*Correlation is significant at the 0.05 level (2-tailed). ${ }^{* *}$ Correlation is significant at the 0.01 level (2-tailed).

Amongst the four factors, only three factors, i.e., General, Social and School self-esteem differed significantly amongst students with different levels of academic performance. Home self-esteem did not differ in terms of academic performance while School selfesteem differed the most on different levels of academic performance.

One may thus conclude that students who showed higher self-esteem also showed significantly higher academic performance. It may be pointed out that many of the factors in school (for example peer influence, teacher-student relation, healthy competition in school, co-curricular activities to show one's competence, etc.) perhaps have contributed significantly to students' performance thus partially validating Hypothesis 2 .

\section{Self-esteem and Socio-Demographic Factors}

Self-esteem and its components were analyzed in terms of socio-demographic factors of the students taken in this sample.

\section{[1]. Total Self-esteem and Age}

There appeared to be considerable difference in the mean scores of total self-esteem in students with respect to age ( $F=11.2, d f=726, p<0.01$ level) which can be attributed to the fact that in middle school there is significant change in the academic pressure from class VII to class VIII.

a) General self-esteem and Age: It was noted to be the highest in 15-year-old students and the lowest in 12 -year-old students $(F=12.4, d f=726, p<0.01)$. This perhaps can be explained in terms of the sudden responsibility to make their choice of the subjects sometimes even against their own wishes and is influenced by peer group. With increasing general awareness and parents' preference versus their own as well as those of their peers, make them confused whether the choice made by them is correct at all. This to an extent can contribute to low General self-esteem. However, as is well known and also researched, these are temporary aberrations and the students gain considerable General self-esteem as they grow up into the later adolescent stage.

b) Social self-esteem and Age: It was noted to be the highest in 17-year-old students and lowest in 12and 13-year-old students $(F=9.55, d f=726, p<0.01$ level). These obtained differences may perhaps be explained in terms of the higher age group students developing a relatively stronger sense of peer association being senior most in the school. They prefer that others know them as being confident, daring and so on, which to an extent are displayed in their skipping the classes, participating in a large number of co-and extracurricular activities during the last year of their school. M ostly they are known to all the teachers in the school and quite often they feel and also are treated like adults in the school.

c) Home self-esteem and Age: It is seen that Home self-esteem was the highest amongst 15- and 17year-old students and the lowest Home self-esteem was found amongst the 13-year-old students ( $t=2.6$, $p \varangle 0.01$ level). This can be explained by the fact that a 13-year-old is treated like a child at home and a 
15-year-old is suddenly made to feel like a grown up due to being in class $X^{\text {th }}$ that is like reaching in adult dimensions. By the time a student is in Class XII ${ }^{\text {th }}$ he is treated like an adult who has to decide about their future career options and work towards it. This enables them to have decision-making responsibility at home like their parents.

d) School self-esteem and Age: As for the school esteem, it was found to be high amongst the 15year-old students and low amongst the 13-year of age students ( $F=3.06, d f=726, p<0.01$ level).

From the analysis it is seen that by and large in most cases, younger the age group lower was the mean selfesteem scores. This could be explained from the fact that at 15-year-old would have opted for their streams, feels and behaves mature in school and wants to be popular amongst students and teachers. Theyare also at the peak of their biological, mental and psychological change from a pre-teen to a post-teen on to adulthood.

[2]. Hypothesis $3\left(a_{2}\right)$ was partially validated which stated that self-esteem scores will differ significantly with regard to the gender of the students. The results showed that except School self-esteem scores ( $t=2.01, p \varangle 0.05$ ) there was no difference between the male and female students on either Total self-esteem or on the other three components of self-esteem.

[3]. When the self-esteem scores were analyzed in terms of family-type to which the students belonged, it was noted that there was a significant difference in Total self-esteem $(t=2.1, p \varangle 0.05)$ and General self-esteem $(t=2.2, p<0.05)$ but not on the remaining three factors. These findings may be due to the fact that in nuclear families, students perhaps can exercise relatively greater self-autonomy as compared to students from joint families. Hence Hypothesis 3 (b) was partially validated which stated that self-esteem scores of students will differ amongst students hailing from two different types of families.

[4]. There was no difference in the self-esteem and its four components in terms of the birth order of the students, thus rejecting Hypothesis 3(c).

[5]. Parental occupation showed no statistical significance on the self-esteem scores and its four components amongst students. Hence Hypothesis 3 (d) was rejected.

[6]. Students' self-esteem scores were assessed with their parents' qualification to see if there was any difference in the self-esteem scores of students in terms of the educational level of the parents. For analysis, educational qualification was divided into (i) school passout (ii) graduate and (iii) postgraduate respectively. Father's qualification did not show any statistically significant difference in the self-esteem scores of students. Students with mother's qualification as a postgraduate showed significantly higher Social self-esteem as compared to students with mothers who were less educated $(F=3.6$, $P \varangle 0.05$ level).

\section{[7]. Academic Performance and Socio-Demographic Factors}

\section{Academic Performance and Age}

Academic performance differed significantly in terms of age of the students $(F=33, d f=726, p<0.01)$. Present research showed that academic performance varied according to the age groups of students, where 12-yearold students performed the highest in the sample ( $M=82.9, S D=11.2$ ) and 17-year-old students performed the lowest in the sample $(M=64.6, S D=15.0)$. This trend can be explained from the fact that there is tremendous pressure from teachers and parents on students of higher age groups to excel, to cope with coaching classes, increasing peer influence, etc., which all leads to a stressful state for an adolescent. This may affect their confidence levels as well as their academic performance. This result validates Hypothesis $4\left(a_{1}\right)$ which states that academic performance of students will vary significantly in terms of their age.

\section{Academic Performance and Gender}

In terms of gender, the academic performance showed that girls did better academically as compared to boys $(t=2.9, p \varangle 0.01)$. This could be attributed to the fact that girls are relatively less involved in non-academic activities in school and are also relatively more prone to listening to the teachers and parents with regard to their study habits, completing assignments, etc. Therefore, the results validate Hypothesis $4\left(a_{2}\right)$, which states that academic performance of students will differ in terms of their gender.

\section{Academic Performance and Family Type}

The Academic performance did not differ in terms of the type of family to which the students belong. Hence the Hypothesis 4 (b) was rejected, which states that academic performance of students will differ in terms of their family type. 


\section{Academic Performance and Birth Order}

First born had significant difference in their academic performance when compared with middle $(t=2.02$, $\mathrm{p}<0.05)$ and last born $(t=2.04, p \varangle 0.05)$ and not as much between the other two. This trend can be explained by the fact in a family there is considerable expectations from the first born in terms of doing well in studies and being a role model for the younger siblings and so on. $M$ aybe this makes these children (first born) work a lot harder, conscientiously and with a certain responsibility that their academic performance is higher than their siblings.

At times such expectations may also lead to stress and pressure that these children may not be higher in academic performance. Thus Hypothesis 4 (c) has been partially validated, which states that academic performance of students will differ in terms of their birth order.

- The academic performance of students did not differ significantly in terms of parental occupation and thus Hypothesis 4 (d) was rejected, which states that academic performance of students will differ in terms of their parental occupation.

- As a part of related findings, it was noted that while academic performance did not vary in terms of father's qualification ( $F=1.16$ ), it however differed in terms of the educational qualification of the mother ( $F=11.5, p \varangle 0.01$ level). Thus, it may be concluded that maternal educational qualification significantly impacts the child's academic performance.

\section{Conclusion}

The present study, which set out to ascertain whether the self-esteem and academic performance were correlated, found that there was a significant correlation between the two, indicating that higher the self-esteem, higher was the academic performance. Self-esteem differed in terms of socio-demographic factors (age, gender and family type) of the students in regard to their academic performance.

Academic performance by itself varied significantly across the different self-esteem factors and some of the socio-demographic variables such as age, gender and birth order.

\section{Limitations and Future Recommendations}

Limitations of this study are listed below:
1. Samples could have been collected from different types of schools such as government, state-run, public and private schools for comparison.

2. Other independent variables such as personality traits and intelligence could have been included as they are closely related to academic performance.

3. The socio-demographic variables could haveclearly focused on the exact occupation, the income of the family, other types of family such as the extended families, etc., to find out both self-esteem and academic performance and the differences thereof in terms of these factors.

4. Educational status and exact occupation could have been taken but due to the non-availability of the data, this could not be accomplished.

Future recommandations of this study are listed below:

1. For future research purpose, intelligence and personality factors can be incorporated in the study to understand the relationship between selfesteem and academic performance.

2. More emphasis can be laid on the family factors, like interpersonal relationship with parents, siblings and significant family members while looking into Home self-esteem and academic performance.

Present research findings are a step in the direction of helping adolescent students in school to develop selfesteem through better social/school environment that will in turn contribute to higher levels of academic performance.

"There is perhaps nothing more important to know about adolescents than that they need to make sense out of their experience." (Branden) ${ }^{3}$

\section{Conflict of Interest: Nil}

\section{References}

1. Allan J, Nairne J. Empowering students: Classroom discussion themes for elementary school teachers and counsellors. Toronto, Ontario: OISE Press 1992.

2. Berndt TJ. Friendship quality and social development. Current Directions in Psychological Science 2002; 11: 7-10.

3. Branden N. The six pillars of self-esteem. Bantam Dell Publishing Group 1995

4. ISBN13: 9780553374391

5. Coopersmith $\mathrm{S}$. The antecedents of self-esteem. San Francisco, CA: W.H. Freeman and Co. 1967.

6. Durkin K. Developmental social psychology. Cambridge, M S: Blackwell 1995. 
7. Ghazvini SD. Relationships between academic selfconcept and academic performance in high school students. Procedia-Social and Behavioral Sciences 2011; 15: 1034-39.

8. Knightley WM, Whitelock DM. Assessing the self-esteem of female undergraduate students: An issue of methodology. Educational Studies 2007; 33(2): 217-31.

9. Mankar J. Impact of self-esteem on scholastic achievement and adjustment of adolescents. International Conference on Management, Economics and Social Sciences (Icmess'2011) Bangkok. 2011; 636-39.

10. Maslow AH. M otivation and personality. New York: Harper \& Row 1970.

11. Osborne JW. Academics, self-esteem, and race: A look at the underlying assumptions of the disidentification hypothesis. Personality and Social Psychology Bulletin, 1995; 21(5): 449-55.

12. Pepi A, Faria L, Alesi M. Personal conceptions of intelligence, self-esteem, and school achievement in
Italian and Portuguese students. San Diego: Adolescence 2006; 41(164): 615.

13. Ross CE, Broh BA. The roles of self-esteem and the sense of personal control in the academic achievement process. Sociology of Education 2000; 73: 270-84.

14. Rubin RA. Stability of self-esteem ratings and their relation to academic achievement: $A$ longitudinal study. Psychology in the Schools 1978; 15(3): 43033.

15. Simpson CK, Boyal D. Esteem construct generality and academic performance. Educational and Psychological Measurement 1975; 35: 897-907.

16. Vishalakshi KK, Yasodhara K. Relationship between self-esteem and academic achievement of secondary school students. Indian Journal Applied Research 2012; 1: 83-84.

Date of Submission: 25 Jul. 2017 Date of Acceptance: $11^{\text {th }}$ Aug. 2017 